\title{
NICOLETTE MAKOVICKY
}

\section{MATERIELLE MINDER}

\section{Om at huske med genstand og krop}

Siden renæssancens genopdagelse af Aristoteles' udlægning af hukommelsen som et permanent aftryk af vore oplevelser, har den vestlige tradition taget det for givet, at genstande kan „bære på minder“ og optræde som aides-des-memoire, dvs. at genstande kan genkalde det glemte eller det fortrængte (se Sorabji 1972). Aristoteles' memoria er en forståelse af hukommelsen som en form for analog katalogisering. I forlængelse af dette er det derfor logisk, at genstande kan opfattes som et analogt vidnesbyrd om et minde eller et stykke information, populært sagt kan genstande ,bære på minder“. Fotografiet kan ses som den fuldendte virkeliggørelse af Aristoteles' memoria gennem brug af moderne teknologi (Forty 1999:3). Yates (1966) har vist, hvordan en forståelse af hukommelse som memoria har været brugt i uddannelsesmæssige sammenhænge siden middelalderen, baseret på ideen om at en rutinemæssig projicering af information på genstande eller visuelle midler kan hjælpe indlæringsprocessen.

Forståelsen af hukommelse som memoria har historisk overskygget Aristoteles' mere problematiske koncept mneme, som dækker den spontane fremkaldelse af minder. Marcel Prousts (1987) kendte beskrivelse af, hvordan smagen og duften af en madeleinekage kan fremkalde barndomsminder, er et eksempel på sådan en mnemotisk påmindelse. Minderne kaldes frem ved en overraskende synæstetisk oplevelse, og resultatet er her en genoplevelse snarere end blot en effektiv genkaldelse.

Prousts eksempel på mnemotisk hukommelse sætter fokus på kroppens rolle i vore bestræbelser på at huske og at mindes. Forstås hukommelse udelukkende som en analog mekanisme til oplagring af information og allerede afsluttede oplevelser, undertrykkes sansernes rolle i fremkaldelsen og udformningen af minder. Den mnemotiske hukommelsesmodel viser også, at genstande fremkalder minder på en inkonsistent og ukontrolleret måde, hvilket gør det svært at fastslå de præcise relationer mellem genstande og minder. De Certeau (1984) forstår hukommelse som en aktiv kraft, der udtrykkes i rum og tid. Minder er ikke afhængige af, at der eksisterer materielle spor efter det, der huskes, men de styrkes af en mangel på spor og af de tomrum, der efterlades, når objekter og personer ikke længere er til stede. Ifølge de Certeau ligger hukommelsen og dens minder ikke begravet i objekter, men er en kreativ kraft, der muliggør en evig cirkulation af associationer mellem genstande og tanker. 
I sommeren 2003 påbegyndte jeg et etårigt feltarbejde i forbindelse med min ph.d-afhandling. En grundig gennemgang af slovakisk etnologisk litteratur og tidligere besøg ledte mig til at udvælge det centrale Slovakiet som feltarbejdsområde. Undersøgelser af slovakisk knipling og kniplinger er hovedsagligt blevet foretaget af etnologer (Kurincova 1983; Marková 1959, 1962; Sedalová 1989; Zajonc 1995, 1997, 2002) og er præget af en interesse for at kortlægge de stilistiske og tekniske variationer, der findes mellem de forskellige regioner. På baggrund af grundigt feltarbejde foretaget sidst i 1950'erne og først i 1960'erne opdelte Marková $(1959,1962)$ slovakiske kniplinger i to hovedgrupper: Bondekniplinger blev lavet af kvinder i rurale områder, hovedsagligt til eget brug, dvs. til dekoration af deres dragter og tekstiler i hjemmet. I det centrale Slovakiet i bjerglandsbyerne omkring byen Banská Bystrica og i det østlige Slovakiet i landsbyen Solivar eksisterede der imidlertid en egentlig kniplingsindustri. De kniplinger, der blevet lavet her, var et produkt rettet mod salg til den borgerlige befolkning, adelen og den omkringliggende rurale befolkning. Kniplingskunsten blomstrede ved siden af den minevirksomhed, der var karakteristisk for begge disse områder, og det ledte Marková til at benævne disse kniplinger minekniplinger. Siden sidst i det 19. århundrede har kniplingskunsten særligt i disse områder vakt interesse hos skiftende politiske regimer fra det østrig-ungarske monarki til efterkrigstidens socialistiske regime. Studier af de organisationer, der blev oprettet for at fremme kniplekunsten og organisere kniplerskerne, har vist, at selvom disse reformer blev fremsat som løsningen på et nationaløkonomisk problem, var de underlagt politiske motiver, der søgte at udnytte kniplingens status som kulturarv til at legitimere den politiske status quo (Zajonc 2002; Makovicky 2004).

En af de landsbyer, hvor denne kniplingsproduktion historisk har fundet sted og stadig finder sted i dag, er Špania Dolina, ${ }^{1}$ der ligger cirka $10 \mathrm{~km}$ nord for provinsbyen Banská Bystrica. Sammen med landsbyen Staré Hory dannede Špania Dolina centrum for den lokale kniplingsindustri. Jeg ønskede ikke primært med mit feltarbejde at undersøge kniplingens tekniske side, men snarere at undersøge cirkulationen (produktion og salg) af kniplingerne samt den måde, de bliver brugt til at udsmykke hjem i det centrale Slovakiet på - både i de førnævnte landsbyer og i Banská Bystrica. Interviews med kniplersker i begge landsbyer samt interviews med deres kunder skulle således danne en stor del af mit materiale. Jeg satte mig selv i lære som kniplerske i begge landsbyer for bedre at kunne forstå materialiteten i den genstand, jeg udforskede, få adgang til informanter og skabe en naturlig ramme for deltagerobservation. Indlæringsprocessen rettede min opmærksomhed mod den intime relation mellem kropslig bevægelse, form og udtryk, der præger knipling som aktivitet. Denne forbindelse mellem kropslig hukommelse og kreativitet, der danner det første tema i denne artikel, er hidtil forblevet ubehandlet.

Mit feltarbejde afslørede ikke alene nye muligheder for at problematisere relationen mellem teknologi, krop og kreativitet, men viste også, at knipling som kunstnerisk aktivitet, både på professionelt niveau og som hobby, i dag vokser i popularitet. Jeg tog til Slovakiet med den forestilling, at der nok kun var få ældre kniplersker i landsbyerne, der stadig praktiserede den særlige kunst at kniple. I stedet erfarede jeg, at kniplekunsten ikke alene er spillevende i landsbyerne omkring Banská Bystrica, men også i selve byen er der flere klubber, hvor kvinder mødes for at kniple og udveksle mønstre. Medlemmerne tager til udstillinger, deltager i særlige kniplingsfestivaler og sælger kniplinger ved markeder og $\mathrm{i}$ butikker. I byens klubber er der stor fokus på, at kniplingsmønstre og teknikker bevares. Dette sker ikke alene, for at de næste generationer kan få mulighed for at udøve dette 
kunsthåndværk, men også for at hjælpe med at huske på det, der menes at være unikt for denne region. Dog er kniplinger meget mere end blot et symbol på en regional identitet, for de opfattes af mine informanter som en form for materiel hukommelse, der hjælper dem til at mindes venner og familie, steder og hændelser.

Kniplinger er „gode at huske med“ på flere niveauer. Materielle genstande forstås populært som noget, der kan fastholde og genkalde associationer, og kniplinger ses derved som en genstand, der kan „bære pä“ minder. I denne artikel viser jeg, hvorledes denne evne til at „fastholde“ minder afhænger af kniplingernes udveksling mellem folk og mellem hjem som led i bestræbelser på at skabe og vedligeholde sociale netværk. For den fagkyndige er de mere end en souvenir. De er snarere en fysisk manifestation af håndværksmæssig viden, der ellers ligger inkorporeret som fysisk, kropslig hukommelse, der vanskeligt kan udtrykkes verbalt. Det er med den sanselige aflæsning af denne viden, jeg begynder denne artikel.

\section{Praktisk viden og kroppens hukommelse}

I det centrale Slovakiet ligger en lille landsby, Špania Dolina, gemt højt oppe på en bjergside og omgivet af skov. Cirka 200 huse, nogle af dem fra 1700-tallet, ligger rundt om landsbyens torv, hvor der findes en lille butik, en kro og et skur, der tjener som posthus. Om vinteren ligger sneen over de små huse som en blød dyne, og der er en fredelig stilhed over det lille samfund. Fra skorstenene stiger røgen mod himlen - hjemme hos de fleste i landsbyen laver man stadig mad på et brændekomfur. Men sneen betyder også tit, at landsbyen bliver afskåret fra hovedvejen, der snor sig forbi langt nede i dalen. Om sommeren kommer der mange turister for at spadsere gennem de smalle gyder, kigge på de gamle landsbyhuse med deres tykke stenmure og små vinduer og indsnuse den rene bjergluft.

I dag fremstår Špania Dolina som „levende kulturarv“, men i 1700-tallet var det en stor, livlig landsby med over 2000 indbyggere. De ældste optegnelser, man har om landsbyen, stammer fra 1200-tallet, da man begyndte at grave efter kobber og sølv i bjerget. I 1500tallet indvandrede store grupper af minearbejdere med deres familier fra det sydlige Tyskland og Moravien, en del af Tjekkiet. Mens mændene arbejdede i de smalle skakter under svære vilkår, supplerede deres koner og børn familiens indkomst ved at kniple. I dag er der ikke længere nogen minevirksomhed i landsbyen - de sidste skakter lukkedes sidst i 1800tallet, men der bliver stadig kniplet i de små huse. Om sommeren sidder landsbykvinderne på bænke i deres haver eller på deres verandaer og knipler i solen. Et par stykker tager endog ned på landsbytorvet hver morgen. Der sidder de og knipler sammen, sludrer og venter på dagens turister.

Ligesom kniplerskerne på Tønderegnen i Danmark, arbejder kniplerskerne i denne landsby i det centrale Slovakiet med en del specialiserede redskaber, når de skaber deres kniplinger. Kniplinger laves på en stor, tøndeformet kniplepude. Traditionelt er den fyldt med sand eller træspåner og en enkelt sten. Den er derfor overraskende tung. I dag er der mange, der fylder den med filt eller gamle klude, men dette giver problemer med stabiliteten, når puden sættes i sit stativ, der ofte er specielt fremstillet af træ. Traditionelt sad puden $i$ en gammeldags rund træsi, der var vendt med bunden i vejret. Stativet rummer tit andre redskaber, såsom sakse, knappenåle, tråde og kniplepinde, når de ikke er i brug. Selve 
kniplingen laves, ved at kniplepinde, om hvilke der er viklet fin linnedtråd, hænges fra knappenåle stukket i puden og sammenflettes. Forskellige slags bindinger dannes, ved at pindene i to par kniplepinde passerer over og under hinanden med regelmæssige mellemrum. Det vigtigste redskab kniplerskerne arbejder med, er det såkaldte furma. ${ }^{2}$ Dette er et smalt stykke hårdt papir, hvori der er prikket huller med bestemte mellemrum over hele fladen, og disse bruges som vejledning for, hvor kniplerskerne skal sætte de knappenåle, de bruger $i$ arbejdsprocessen. Disse nåle placeres efter en eller flere bindinger og er medvirkende til, at kniplingen ikke trækker sig sammen under arbejdsprocessen. Kniplinger laves, uden at der bindes knuder, og selve deres form skyldes udelukkende den friktion, der skabes, når trådene flettes sammen og strækkes ud mellem knappenålene. Tønderkniplinger laves også ved hjælp af et sådant stykke papir, et kniplebrev. Forskellen mellem de kniplebreve, man finder til fremstilling af tønderske kniplinger, og dem, der laves i Špania Dolina, ligger ikke alene i stilmæssige forskelle. Tønderske kniplebreve kan kun bruges til at lave et enkelt mønster, medens kniplebrevet i Špania Dolina er universelt. Det vil sige, at alle kniplinger kan skabes på baggrund af et enkelt furma. Det er en væsentlig forskel, for det betyder, at kniplerskerne ikke behøver at vælge, hvilket mønster de ønsker at lave, før de begynder. Kniplerskerne i Špania Dolina skaber nye mønstre ved at kombinere motiver alt efter valg, indtil kniplingen er bred nok, eller indtil de synes, at den er æstetisk tilfredsstillende. I landsbyen følger kniplerskerne næsten aldrig trykte mønstre. De genskaber kun bestemte mønstre, hvis de sælger godt, eller hvis de er blevet bestilt af en kunde. Med andre ord er det at designe et nyt mønster en helt almindelig del af arbejdsprocessen ved skabelsen af Špania Dolina-kniplinger.

Feltarbejdet viste mig, at teknisk kunnen var forbundet med kniplerskernes evne til at indarbejde de bevægelser, der skal til for at skabe de rette bindinger. For at lave et bestemt mønster skal man også kunne huske en helt bestemt kombination af bindinger, dvs. en bestemt kombination af bevægelser. Dette ligger til grund for al kniplingskunst lige meget, hvilken stil man bestemmer sig for at udøve, men det er specielt vigtigt for kniplinger i den tradition, der kommer fra Špania Dolina. Brugen af den universelle form for kniplebrev betyder nemlig, at kniplerskerne i Špania Dolina, og de, der knipler ved hjælp af denne teknik i byen Banská Bystrica, hverken har en tegning eller markeringer, de kan holde sig til, når de påbegynder deres arbejde. Med andre ord skal kniplerskerne ikke kun have et repertoire af motiver, de kan bruge, når de skaber en ny knipling, og en idé om, hvordan disse kan kombineres, men de skal være indarbejdet som rytmiske bevægelser i deres kropslige hukommelse.

Andre har før argumenteret for, at form er et produkt af relationen mellem de præcise, kontrollerede bevægelser, tekniske hjælpemidler og materialet, hvoraf genstanden skabes, snarere end at være resultatet af et allerede udformet mentalt billede (fx Semper 1860, 1863; Boas 1955; Ingold 2000). I dette tilfælde er det klart, at kniplinger kan ses som en materialisering af rytmisk organiseret fysisk bevægelse. Både brugen af det universelle kniplebrev og tendensen til konstant at designe nye mønstre, snarere end at reproducere eksisterende kniplinger, synes at tale imod, at kniplerskerne udformer et mentalt billede af kniplingen, før de påbegynder deres arbejde.

Den arbejdsproces, kniplingerne er et resultat af, opleves på en helt særlig måde af mine informanter, uanset om de er fra landsbyen Špania Dolina eller fra Banská Bystricas urbane miljø. De beskriver knipling som både en besættelse og en form for terapeutisk aktivitet. Flere informanter fortalte, at de tit fandt det svært at falde i søvn, hvis et bestemt 
mønster voldte særlige problemer. De fortalte, at de ofte sad og arbejdede med et mønster hele natten, for det var umuligt for dem at falde til ro, før problemet var løst. De beskrev arbejdsprocessen ved at sige, at de, glemte tiden og tit hverken var klar over, hvor længe de havde siddet ved kniplepuden, eller hvad der foregik omkring dem. Csikszentmihalyi har beskrevet netop dette fænomen - tabet af fornemmelsen af tid og omgivelser - som optimal koncentration og døbt det flow (Csikszentmihalyi 1975). En person oplever en flowfornemmelse, når der er balance mellem deres evner og den udfordring, en aktivitet indeholder. En tredje effekt af denne flowfornemmelse, som beskrives af Csikszentmihalyi, er, at personer oplever et tab af deres selvbevidsthed. Jeg erfarede, at de fleste af mine informanter havde fattet interesse for at kniple på det tidspunkt, hvor de blev gift og stiftede familie, men at de for alvor blev ,,bidt““ (et ord, de selv brugte), da de oplevede et radikalt brud i deres hverdag. Dette kom oftest i form af et dødsfald i den nærmeste familie, skilsmisse elle pensionering. Knipling, forklarede mange, ledte tankerne væk fra sorg og problemer, da det krævede ens fuldstændige opmærksomhed. Med andre ord er det ikke alene flowfornemmelsen, der gør knipling så attraktiv en aktivitet for mange af mine informanter, selve arbejdet udgør også en situation, de forstår at udnytte emotionelt.

Den håndværksmæssige viden, der skal til for at skabe kniplinger ligger i kroppen som en form for fysisk hukommelse på samme måde som den viden, der skal til for at gå, cykle eller danse tango. Dormer (1997) har påpeget, at denne form for praktisk viden er uegnet til at udtrykkes verbalt. Både jeg og andre, der lærte at kniple hos ældre kniplersker i landsbyen Špania Dolina, erfarede, at de til tider havde svært ved at formulere klare forklaringer og instrukser. Det var svært for dem at videregive den tekniske viden, både fordi den er så intimt forbundet med kropslig bevægelse, og fordi den i så høj grad er processuel. Dette betyder dog ikke, at kniplingerne selv, kniplebrevet eller et tegnet mønster ikke giver præcise tekniske informationer. På samme måde som kniplersker tit finder det nemmere at vise, hvordan en binding eller et motiv skal kniples, er det nødvendigt for kniplerskerne fysisk at genskabe et stykke knipling for at forstå dets mønster. Selvom de kan udlæse fra selve kniplingen, hvilken teknik der er blevet brugt, hvilken landsby kniplingen stammer fra, og hvilke motiver der optræder, betyder det ikke, at de har information nok til at kunne give en præcis opskrift på, hvordan dette mønster skal kniples. Den viden, der skal til, for at skabe et mønster bliver båret af selve den materielle genstand, nemlig kniplingen, og kan kun tilegnes gennem fysisk rekonstruktion af dens materialitet gennem en disciplinering af kroppen til at udføre de rette bevægelser.

For kniplersker bærer kniplingerne på denne måde på den information, der skal til, for at genskabe dem. I og med at de er en materialisering af rytmiske bevægelser, er de også en materialisering af den tekniske viden, der ligger som kropslig hukommelse i form af inartikulerbare kropslige rutiner. Umiddelbart ser det ud til, at relationen mellem kniplinger som materiel genstand og den praktiske viden, der er med til at skabe dem, er et direkte eksempel på memoria: For dem, der har den nødvendige tekniske kunnen, er kniplingerne en katalogisering eller en oplagring af information, der svarer til den, der bæres af skaberen. Medtænker man imidlertid den store rolle, improvisation spiller i arbejdsprocessen, samt den klare vigtighed af repetition og praktisk genskabelse i overførelsen af viden, bliver det klart, at der er en anden relation på spil. Nøglen til forståelse er en fysisk genskabelse af selve den proces, der skaber et mønster. Med andre ord har vi ikke at gøre med en situation, hvor allerede udformede kreative tanker overføres på en genstand. Her er kroppen et medium for både skabelsen af nye genstande og for ,,aflæsning“ af informationer om 
dem. Forståelse og tilegnelse af ny viden opleves som opnået ved en flowfornemmelse, der opstår, når de rette bevægelser er blevet tilpas rutinerede. Med andre ord udløser den materielle form en fysisk rutine, der i høj grad opleves som sanselig og emotionel.

\section{Hjemmet - mindernes rum?}

Kniplinger ses imidlertid som mere end materialiseret kropslig hukommelse, der kan udlæses af den fagkyndige. Hjemmet og dets indretning opfattes i det centrale Slovakiet som hovedsagligt af interesse for det kvindelige overhoved i familien. Studier af kvinders deltagelse på arbejdsmarkedet, i politik og organisationer, der arbejder for at fremme kvinders lighed, viser, at det postsocialistiske Slovakiet, i lighed med hele det central- og østeuropæiske område, er præget af en overraskende konservativ tilgang til kønsroller (Einhorn 1993; Havelková 1993; Heitlinger 1993; Hughes 1990; Occhipinti 1996; Wolchik 1998). Slovakiet præges af en stærk antifeminisme, der viste sig klart i mine informanters understregning af hjemmet som et feminint rum, hvor kvinder bedre kan realisere sig selv, end de kan på arbejdsmarkedet. Kvinder forstås ikke blot som dem, der har det sidste ord, når det kommer til valg af indretning, men det er også dem, der står for rengøring og vedligeholdelse af hjemmet. På den måde forstås hjemmet som en afspejling af en kvindes sans for indretning og æstetiske præferencer, men også som et vidnesbyrd om hendes kundskaber som partner, moder og socialt individ. Kniplinger - om de er borter på duge, lyseduge eller hænger indrammet på væggen - er genstande, man finder i alle husholdninger i Špania Dolina og i de fleste i Banská Bystrica. I nogle husstande, især dem, hvor der er småbørn, tages kniplingerne kun frem fra deres skuffe ved specielle lejligheder. Til hverdag erstattes de med billige maskinvævede udgaver eller plastikimitationer. Børn og teenagere, forklarede mine informanter, har endnu ikke forstået kniplingernes ,værdi“. I denne „værdi“" ligger der langt mere end blot kniplingernes købspris.

I andre hjem er kniplinger en permanent del af indretningen. Duge draperes diskret over kaffeborde, ofte diagonalt, således at to kanter ligger på bordet, medens de to andre hænger ud over kanten frit mod gulvet. Potteplanter, vaser og porcelænsfigurer på familiens reoler står tit på kniplede lyseduge. Vigtige er også små runde kniplinger, der lægges ind under det fine porcelæn og vinglas i den vitrine, der konkurrerer med enhver families fjernsyn om at være centrum i dagligstuen. Disse kniplinger lever tit side om side med hæklede og broderede småduge, der tillige spredes ud over alle træflader i hjemmet. Kniplingerne opfattes dog som „finere“. Dette skyldes, at mens hækling og broderi er udbredte håndarbejdsformer, som de fleste kvinder kan udføre, har knipling altid været et specialiseret håndværk udført i geografisk begrænsede områder. Selvom knipling siden 1970'erne er blevet en populær hobby, er det stadig en langt mindre udbredt form for håndarbejde end broderi og hækling.

En konsekvens af dette er, at de fleste kniplinger ikke bruges i det hjem, hvor de bliver skabt. I betragtning af at hjemmet ses som et billede på det arbejde, familiens kvindelige overhoved lægger i at skabe et hjem og derved familielivet som helhed, er det interessant at observere, at de fleste kniplinger kommer ind i et hjem som gave snarere end som noget, der er bestilt til hjemmet af kvinderne selv. Kniplinger ses som en god fødselsdagsgave og jubilæumsgave til kolleger og venner af begge køn. Desuden bliver mange kniplinger givet som tak for tjenester, folk gør for hinanden. Dette kan både være praktisk, fysisk 
arbejde og tjenester som fx at skaffe en børnehaveplads eller en praktikplads. Studier af socialistiske og postsocialistiske lande i Central- og Østeuropa har vist, at netværk er karakteristiske for disse samfund (Humphrey 1998; Ledeneva 1998; Verdery 1996). Ledeneva har betegnet disse netværk som economies of favours (tjenesteøkonomier) og har beskrevet deres opståen i det tidligere USSR som en følge af en mangel på forbrugsgoder og serviceydelser under kommunismen. Disse netværk har overlevet kommunismens fald og er blomstret på grund af den økonomiske nedtur, der fulgte skiftet fra planøkonomi til et frit marked. Disse netværk var også en del af dagligdagen i det kommunistiske Tjekkoslovakiet og er stadig en fast del af det sociale liv. Disse netværk danner en alternativ $ø$ konomi, i og med at de giver folk mulighed for at få adgang til goder og service, de ellers ikke har råd til eller havde ret til. Karakteristisk for denne økonomi er det tydelige moralistiske islæt: En tjeneste gengældes enten med en ny tjeneste eller med en gave, men aldrig med betaling. Personerne i et netværk beskrives altid som venner, familie eller bekendte, og der gøres store bestræbelser på at understrege, at relationen mellem folk ikke er baseret på en simpel udveksling af goder, men i virkeligheden ligger uden for udvekslingssituationen.

Mine informanter forklarede, at kniplinger er en god gave, fordi de minder en om den, der har givet dem. De fleste af mine informanter, også dem, der ikke selv knipler, men ejer og bruger kniplinger i deres husholdning, forstår kniplinger som en genstand, der kan „bære på“ minder. Hvis man således vælger at give en, man holder af, en kniplingsbesat dug eller blot en lysedug, kan man være sikker på, at den pågældende kommer til at huske på en, så længe dugen består. Her spiller kniplingernes materialitet helt klart en særlig rolle; de kan blive til en genstand, der forankrer et minde om en person eller en hændelse, fordi de også består efter selve overrækkelsen. De konsumeres ikke på samme måde som en god flaske vin eller en æske chokolade. Mine informanters beskrivelser af deres kniplinger som ,materielle minder" viser, at de opfatter hukommelsen som noget, der arbejder på samme måde som Aristoteles' memoria: Kniplingerne har den rolle, at de materialiserer et minde og derved gør det holdbart.

I mange hjem finder man også, at kniplingsbesatte tekstiler, om det så er finere sengelinned, borddækning eller folkedragter, nedarves fra generation til generation. Her optræder kniplinger som alle andre former for arvegods, der minder deres ejere om deres afdøde nære. Mine ældre informanter opbevarer disse tekstiler foldet i stakke på hylder i specielle linnedskabe i dagligstuen. I de fleste hjem, specielt i Banská Bystrica, hvor den største del af befolkningen bor i lejligheder, er det dog mest almindeligt, at husets linned opbevares i hjemmets største soveværelse. Her deler arvegods plads med de tekstiler, de fleste kvinder har fået i medgift, da de blev gift og skulle etablere deres eget hjem. Denne medgift består af praktiske tekstiler såsom sengelinned og håndklæder, men også af dekorative tekstiler såsom duge og lyseduge. Traditionelt blev denne medgift skabt af brudens mor allerede i hendes barndom, og det blev forventet af den unge pige, at hun skulle interessere sig for indsamlingen og forarbejdningen af tekstiler, efterhånden som hun blev mere moden. I dag forstås det ikke længere som en nødvendighed at samle en medgift, men det er stadig normal praksis. Mine informanter beskrev ofte indsamlingen af deres medgift som en modningsproces: Mens de som teenagere havde opfattet det som en gammeldags og unødvendig tradition, beskrev de, hvordan de langsomt fattede interesse for medgiften, efterhånden som de blev ældre og nærmede sig giftealderen. Indsamlingen af en medgift er både et tegn på seksuel modenhed og på en villighed til at påtage sig rollen som husmoder, ligesom det er et middel til indlæringen af denne rolle. 
Bachelard (1964) har beskrevet linnedskabet som et intimt rum, hvor fortiden, nutiden og fremtiden flyder ud i et. Her hersker en orden, som ikke blot er geometrisk, men som „husker familiens historie“(Bachelard 1964:79). Mit feltarbejde viste mig, at dette vitterligt er sandt. Mine bestræbelser på at placere kniplinger i en større kontekst, hvad angik huslige tekstiler, endte tit med, at mine informanter åbnede deres linnedskab og fremviste dets indhold. Hver gang fulgte en detaljeret mundtlig overlevering af familiens slægtshistorie. Efterhånden som tekstilerne blev taget ud af skabet, blev historien udfoldet stykke for stykke, i og med at hver genstand udløste nye minder og derved en ny fortælling. Således blev familiens genealogi spredt ud foran mine øjne i form af nye og gamle tekstiler, før de igen blev foldet, ordnet og lagt ind i skabet.

På tværs af hjem og generationer finder kniplinger således deres plads enten som en udsmykning af hjemmet eller gemt væk i et skab. Når mine informanter ser deres kniplinger, ser de ikke alene en genstand, som de kan bruge til at æstetisere deres hjem med, men en materialisering af den handling, der gjorde, at kniplingsgenstanden kom ind i huset. Med andre ord er associationen mellem genstanden og den person, der enten skabte den eller gav den som gave, særligt stærk. Man kan sige, at de kniplinger, der bruges i indretningen af hjemmet, repræsenterer en slags aflejring af en persons og en families sociale netværk både $\mathrm{i}$ rum og i tid.

Dog er jeg ikke sikker på, at dette er en udtømmende beskrivelse. Selvom mine informanter gang på gang beskrev deres kniplinger som knyttet til en særlig person eller lejlighed, så fandt jeg, at der også var et stort pres fra omverdenen, der stadig søgte at vriste disse tekstiler fra dem. Det var ikke ualmindeligt, at kniplinger blev givet væk til familie og venner, hvis de havde udtrykt interesse for en bestemt dug eller lysedug. Udnyttelsen af ens kontaktnetværk betød, at der måtte findes en gave, og det var almindeligt at give læger gaver under eller efter en behandling. Ligeledes ansås det for nødvendigt at give gaver til lærerne ved skoleårets afslutning og efter afsluttende eksaminer. Disse gaver beskrives som en tak for den ,ekstra indsats“, disse mennesker siges at have gjort. Ethvert spørgsmål om, at det kunne ligne en form for bestikkelse, afvises bestemt. Men samtidig hører man tit, at det er nødvendigt at give en sådan gave, medmindre man vil risikere, at denne „ekstra indsats“ udebliver. Med andre ord opstod der med regelmæssige mellemrum situationer, hvor det krævedes, at man havde en gave liggende parat derhjemme.

Weiner har udviklet begrebet inalienable possession, som bedst kan oversættes til dansk som en genstand, der er uafhændelig eller umistelig (Weiner 1989). En uafhændelig genstand er ifølge Weiner en genstand, som er stærkt forbundet med identiteten hos den eller dem, der ejer den. Det, der gør den særlig, er, at den rummer associationer til en række ejere over tid. Den er med andre ord en umistelig genstand, en genstand, der tilbageholdes fra enhver form for cirkulation. Med Weiners teoretiske briller bliver det klart, at der er to kategorier af kniplingsgenstande. Den ene udgøres af de kniplinger, der cirkulerer frit mellem hushold - fragmenter, der kan absorberes i et hjem som symbol på de sociale relationer, husholdet er en del af, og derefter løsrives og sendes videre for aktivt at genskabe og vedligeholde disse relationer. Den anden kategori dannes af de kniplinger, der forbliver i familien og går i arv gennem flere generationer. Disse kan betegnes som umistelige.

Den ,aflejring“" af sociale relationer i tid og rum, som kniplingerne synes at repræsentere, er derfor kun et øjebliksbillede af en proces, der præges af cirkulation og bevægelse. Hvis de minder om hændelser og personer, kniplingerne synes at bære på, er bundet til deres 
materialitet, sådan som mine informanter foreslår det, ville det betyde, at minderne ville blive glemte, og de sociale relationer, de står for, ikke længere ville kunne bestå, når de blev cirkuleret. Det viser sig dog, at det netop er bevægelsen mellem hjem og mellem generationer, der styrker relationerne mellem folk.

De Certeau (1985) har beskrevet hukommelse som et ,antimuseum“, i og med at den ikke kan lokaliseres i en genstand eller et rum. Hukommelse hverken katalogiserer eller placerer hændelser efter en lineær tidsmodel, men tager fragmenter af det oplevede og skyder dem frem i nutiden i vilkårlig rækkefølge. Han påpeger, at hukommelsen ikke handler om det allerede afsluttede, dvs. om fortiden, men om nutiden. Hukommelsen er den samtidige eksistens af flere tider (de Certeau 1984:82). De Certeaus forståelse af hukommelse er til dels mnemotisk, $\mathrm{i}$ og med at den kannibaliserer almindelig praksis og sniger sig ind $\mathrm{i}$ de åbninger og tomrum, der præger vores indtryk og omgang med omverdenen: Hukommelsen arbejder kun, når der er noget, der sætter den i gang, og dens objekt huskes kun, når det ikke længere er til stede. Relationen mellem en given genstand og de associationer, den fremkalder, er ikke bundet, men kontekstuel. Hos de Certeau arbejder hukommelsen med det materielle - som et barn med et sæt Legoklodser - ved at flytte rundt på det, danne associationer mellem fragmenter og derefter koble dem fra hinanden.

Hvis fotografiet er en virkeliggørelse af Aristoteles' memoria, er mine informanters linnedskab, der kan ,,huske“ slægtshistorien, et eksempel på de Certeaus’ fragmenterede og vilkårlige hukommelse forstået som samtidig eksistens af flere tider. I skabet ligger gammelt og nyt, arvegods og indkøbte tekstiler, medgift, der venter på at videregives. Det er dog ikke linnedskabets orden, der understøtter mine informanters hukommelse, snarere er det, når denne orden lejlighedsvis forstyrres, at minderne bringes frem.

Måden, hvorpå de cirkulerende kniplingsbesatte lyseduge indgår i den æstetiske helhed i snart det ene hjem, snart et andet, synes også at have mere til fælles med de Certeaus hukommelsesmodel end med Aristoteles' memoria. Mine informanter taler om kniplinger som et materielt minde om en person eller en hændelse, men dette er måske ikke så overraskende. Hele pointen med at give en sådan gave er at prøve at sikre sig, at den pågældende person bliver ved med at huske deres fælles relation i et positivt lys. En kniplet lysedug givet som tak for en tjeneste er ikke en afslutning på en relation. Det er en forsikring om, at denne relation kommer til at bestå i fremtiden.

Mine informanter synes således at tale om nutiden, endog om fremtiden, når de taler om fortiden. De kniplede lyseduge og linnedskabet skal ikke udelukkende opfattes som et arkiv, men som en ressource. Kniplede genstande kan medvirke til at forankre individet i sociale relationer, familiehistorie og endda et geografisk sted, men disse associationer er ikke absolutte. Tværtimod skabes de konstant på ny, og der dækkes over deres skrøbelighed, ved at kniplingernes materialitet påkaldes for at vidne om deres eviggyldighed. Materialiteten bruges således af mine informanter som et diskursivt kneb, gennem hvilket de kan forstå deres nutidige praksis og fremtidsplaner som forankret i en konkret fortid.

\section{Noter}

1. Udtales med et blødt s, som det engelske $s h$.

2. Udtales som på dansk. 


\section{Litteratur}

Bachelard, Gaston

1964 The Poetics of Space. New York: Orion Press.

Boas, Franz

1955 [1927] Primitive Art. New York: Dover Books.

Csikszentmihalyi, Mihaly

1975 Enjoyment and Intrisic Motivation. I: M. Csikszentmihalyi (eds.): Beyond Boredom and Anxiety. San Francisco: Jossey-Bass Publishers.

de Certeau, Michel

1984 The Practice of Everyday Life. London: University of California Press.

1985 Practices of Space. I: M. Blonsky (ed.): On Signs. Baltimore: Johns Hopkins University Press

Dormer, Peter

1997 Craft and the Turing Test for Practical Thinking. I: P. Dormer (ed.): The Culture of Craft. Manchester: Manchester University Press.

Einhorn, Barbara

1993 Cinderella Goes to Market: Citizenship, Gender and Women's Movements in East Central Europe. London: Verso.

Forty, Adrian

1999 Introduction. I: A. Forty \& S. Küchler (eds.): The Art of Forgetting. Oxford: Berg.

Havelková, Hana

1993 A Few Prefeminist Thoughts. I: N. Funk \& M. Mueller (eds.): Gender Politics and Post-Communism. London: Routledge.

Heitlinger, Alena

1993 The Impact of the Transition from Communism on the Status of Women in The Czech and Slovak Rebublic. I: N. Funk \& M. Mueller (eds.): Gender Politics and Post-Communism. London: Routledge.

Hughes, Zuzana

1990 Education for Parenthood in Czechoslovakia. I: B. Deacon \& J. Szalai (eds.): Social Policy in the New Eastern Europe. What Future for Socialist Welfare? Aldersholt: Avebury.

Humphrey, Caroline

1998 Creating a Culture of Disillusionment. Consumption in Moscow 1993. A Chronicle of Changing Times. I: D. Miller (ed.): Worlds Apart. Modernity Through the Prism of the Local. London: Routledge.

Ingold, Timothy

2000 Making Culture and Weaving the World. I: P. Graves-Brown (ed).: Matter, Materiality and Modern Culture. London: Routledge.

Kurincová, Elena

1983 Èipkárske školy na slovensku (Knipleskoler i Slovakiet). Zborník slovenského národného múzea LXXVII(23):247-63.

Ledeneva, Alena

1998 Russia’s Economy of Favours. Cambridge: Cambridge University Press

Makovicky, Nicolette

2004 Cultural Distinctiveness: The Case of Slovakia. Nord Nytt. Nordisk tidsskrift for Etnologi og Folkloristik 91:63-79. 
Markova, Ema

1959 Palièkovana èipka v slovenskej l‘udovej umeleckej výrobe (Kniplinger i Slovakiets folkekunst). Bratislava: UL'UV.

1962 Slovenské èipky (Slovakiske kniplinger). Bratislava: SVKL.

Occhipinti, Laurie

1996 Two Steps Back? Anti-feminism in Eastern Europe. Anthropology Today 12(6):1318 .

Proust, Marcel

1987 A la Recherche du Temps Perdu. Paris: Laffont

Sedalová, Ludovita

1989 Èipky (Kniplinger). Národopisné Informacie 1(89):83-97.

Semper, Gottfried

1860 Der Stil in den technischen und tektonischen Künsten; oder, Praktische Aesthetik: Ein Handbuch für Techniker, Künstler und Kunstfruende. Vol. 1. Frankfurt am Main: Verlag für Kunst und Wissenschaft.

1863 Der Stil in den technischen und tektonischen Künsten; oder, Praktische Aesthetik: Ein Handbuch für Techniker, Künstler und Kunstfruende. Vol. 2. München: F. Bruckmann.

Sorabji, Richard

1972 Aristotle on Memory. London: Duckworth.

Verdery, Katherine

1996 What was Socialism and What Comes Next? Princeton: Princeton University Press.

Weiner, Anette

1989 Inalienable Possessions. Oxford: University of California Press.

Wolchik, Sharon

1998 Women and the Politics of Transition in the Czech and Slovak Republics. I: M. Rueschmeyer (ed.): Women in the Politics of Postcommunist Eastern Europe. London: M.E. Sharpe, Inc.

Yates, Francis

1966 The Art of Memory. Harmondsworth: Penguin.

Zajonc, Juraj

Niektoré europské paralely súèasného èipkarstva na slovensku (Ligheder mellem knipling i Europa og Slovakiet). Slovenský národopis 4:461-70.

$1997 \quad$ Niektoré paralelly rol'nickych èipiek v Honte (Ligheder i bondekniplinger fra Hontregionen). Slovenský Narodopis 4:345-56.

$2002 \quad$ Nové podnety vo vývoji palièkovanej èipky na území slovenska na prelome 19. a 20. storoèia, I: E. Hercigonja-Mišik (ed.): Proceedings of the Conference The Central Lacemaking Course in Vienna. History, Work and Reception in the Countries of the Austro-Hungarian Monarchy. Zagreb: Kratis. 